\title{
TLR4 antagonist reduces early-stage atherosclerosis in diabetic apolipoprotein E-deficient mice
}

\author{
Zhongyang Lu ${ }^{2}$, Xiaoming Zhang ${ }^{2}$, Yanchun $\mathrm{Li}^{2}$, Junfei $\mathrm{Jin}^{2}$ and Yan Huang ${ }^{1,2}$ \\ ${ }^{1}$ Ralph H. Johnson Veterans Affairs Medical Center, Charleston, South Carolina 29401, USA ${ }^{2}$ Division of \\ Endocrinology, Diabetes and Medical Genetics, Department of Medicine, Medical University of South Carolina, 114 \\ Doughty Street, Charleston, South Carolina 29403, USA
}

Correspondence should be addressed to $Y$ Huang

Email

huangyan@musc.edu

\begin{abstract}
Although it has been reported that deficiency of toll-like receptor 4 (TLR4) is associated with reduced atherosclerosis in atherosclerosis-prone mice and attenuated pro-inflammatory state in diabetic mice, it remains undetermined whether treatment with a TLR4 antagonist reduces atherosclerosis in nondiabetic or diabetic mice that have TLR4 expression. In this study, we determined the effect of Rhodobacter sphaeroides lipopolysaccharide (Rs-LPS), an established TLR4 antagonist, on early-stage atherosclerosis in nondiabetic and streptozotocin-induced diabetic apolipoprotein E-deficient $\left(\mathrm{Apoe}^{-{ }^{-}}\right)$mice. Analysis of atherosclerotic lesions of both en face aortas and cross sections of aortic roots showed that administration of Rs-LPS in 14-week-old diabetic Apoe ${ }^{-1-}$ mice for 10 weeks significantly reduced atherosclerotic lesions. Although atherosclerotic lesions in nondiabetic Apoe ${ }^{-1-}$ mice appeared to be decreased by Rs-LPS treatment, the difference was not statistically significant. Metabolic study showed that Rs-LPS significantly lowered serum levels of cholesterol and triglycerides in nondiabetic mice but not in diabetic mice. Furthermore, immunohistochemistry studies showed that Rs-LPS inhibited the expression of interleukin 6 and matrix metalloproteinase- 9 and reduced the content of monocytes and macrophages in atherosclerotic plaques. Taken together, this study demonstrated for the first time that TLR4 antagonist inhibited vascular inflammation and atherogenesis in diabetic Apoe ${ }^{-/-}$mice and lowered serum cholesterol and triglyceride levels in nondiabetic $A p o e^{-1-}$ mice.
\end{abstract}

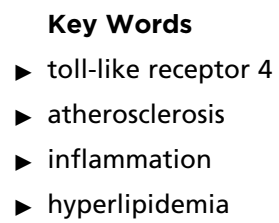

Journal of Endocrinology (2013) 216, 61-71

\section{Introduction}

Early epidemiological studies showed an association between infection with gram-negative bacteria and atherosclerosis (Mendall et al. 1995), suggesting that toll-like receptor 4 (TLR4), a receptor for lipopolysaccharide (LPS) from gram-negative bacteria, is involved in atherosclerosis. It was proposed that bacteria such as Chlamydia pneumonia and Porphyromonas gingivalis might promote atherosclerosis by activating TLR4 and TLR4mediated inflammation via LPS. In recent years, animal studies with atherosclerosis-prone mice have provided strong evidence that TLR4 plays an important role in atherosclerosis. It has been demonstrated that deficiency of TLR4 or MyD88 in apolipoprotein E-deficient $\left(\mathrm{Apoe}^{-/-}\right)$mice is associated with a significant reduction of atherosclerosis (Bjorkbacka et al. 2004, Michelsen et al. 2004, Higashimori et al. 2011). As no LPS or LPS-enriched gram-negative bacteria was given to the mice, these studies suggested that TLR4 was activated

Published by Bioscientifica Ltd. 
by endogenous ligands that are likely to be related to hyperlipidemia in $A p o e^{-/-}$mice. Indeed, in vitro studies have shown that minimally modified LDL (mmLDL) is capable of inducing inflammatory cytokine production in macrophages by engaging TLR4 (Miller et al. 2003, 2005). Besides atherosclerosis, studies of diabetes in animal models have shown that deficiency of TLR4 is also associated with attenuation of the pro-inflammatory state of diabetes (Zipris 2010, Devaraj et al. 2011, Grieco et al. 2011). Thus, TLR4 appears to be a key player in the inflammatory processes contributing to both atherosclerosis and diabetes.

Although the knockout models have shown that the inborn deficiency of TLR4 is related to reduced atherosclerosis, it remains unknown whether administration of TLR4 antagonists in mice with normal TLR4 expression is effective to impede atherosclerosis. Furthermore, as diabetes accelerates atherosclerosis by increasing vascular inflammation (Kanter et al. 2012), it is more intriguing to determine whether administration of TLR4 antagonists is also effective to reduce diabetes-accelerated atherosclerosis.

In this study, we treated 14-week nondiabetic and diabetic Apoe ${ }^{-/-}$mice with Rhodobacter sphaeroides LPS (Rs-LPS), an established TLR4 antagonist (Baker et al. 1990, Kirkland et al. 1991, Aida et al. 1995, Hammad et al. 2009, Hutchinson et al. 2010), for 10 weeks to determine the effect of TLR4 blockade on the early-stage atherosclerosis. We found that treatment with Rs-LPS reduced atherosclerotic lesions in diabetic $\mathrm{Apoe}^{-/-}$mice.

\section{Materials and methods}

\section{Cell culture}

Human aortic endothelial cells (HAECs; Invitrogen) were grown in Medium 200 with low serum growth supplement containing $2 \%$ fetal bovine serum, $1 \mu \mathrm{g} / \mathrm{ml}$ hydrocortisone, $10 \mathrm{ng} / \mathrm{ml}$ human epidermal growth factor, $3 \mathrm{ng} / \mathrm{ml}$ basic fibroblast growth factor, and $10 \mu \mathrm{g} / \mathrm{ml}$ heparin. HAECs were maintained at $37^{\circ} \mathrm{C}$ with $5 \% \mathrm{CO}_{2}$ and $95 \%$ humidity and $100 \%$ confluent cultures were used for experiments. HAECs were treated with $100 \mathrm{ng} / \mathrm{ml} \mathrm{LPS}$ (Sigma-Aldrich) in the absence or presence of anti-TLR4 antibody ( 5 or $10 \mu \mathrm{g} / \mathrm{ml}$; R\&D Systems, Minneapolis, MN, USA) or Rs-LPS (100 or $500 \mathrm{ng} / \mathrm{ml}$; InvivoGen, San Diego, CA, USA) for $24 \mathrm{~h}$. Human U937 mononuclear cells (American Type Culture Collection, Manassas, VA, USA) were cultured in a 5\% $\mathrm{CO}_{2}$ atmosphere in RPMI 1640 medium (Gibco, Invitrogen Corp.) containing 10\%
FCS, 1\% MEM nonessential amino acid solution, and $0.6 \mathrm{~g} / 100 \mathrm{ml}$ HEPES.

\section{ELISA}

Interleukin 6 (IL6) in medium was quantified using sandwich ELISA kits according to the protocol provided by the manufacturer ( $R \& D$ System).

\section{Animals, diet, and treatments}

Male $A p o e^{-/-}$mice were purchased from Jackson Laboratory (Bar Harbor, ME, USA) and housed at the animal facility of VA Medical Center in Charleston, SC, USA. Only male mice were used in this study because female $A p o e^{-/-}$ mice are resistant to streptozotocin (STZ) treatment (Goldberg et al. 2004). The animal protocol was approved by the Institutional Animal Care and Use Committee (IACUC). All mice were maintained on a $12 \mathrm{~h}$ light:12 h darkness cycle in a pathogen-free environment and had ad libitum access to water and regular mouse chow (8604 Teklad rodent diet, Harlan Laboratories, Indianapolis, IN, USA). The study began when mice were 9 weeks old and ended when mice were 24 weeks old. $A p o E^{-/-}$mice were randomly divided into four groups: 1) nondiabetic control mice, 2) nondiabetic mice treated with Rs-LPS, 3) diabetic control mice, and 4) diabetic mice treated with Rs-LPS. At the age of 9 weeks, mice in groups 3 and 4 were rendered diabetic by i.p. administration of STZ $(50 \mu \mathrm{g} / \mathrm{kg}$ in citrate buffer, $0.05 \mathrm{~mol} / \mathrm{l}, \mathrm{pH} 4.5$; SigmaAldrich) and mice in groups 1 and 2 were given an equivalent amount of citrate buffer for 5 days. Five weeks after STZ treatment, mice in groups 2 and 4 were treated by i.p. administration of Rs-LPS ( $1 \mu \mathrm{g} /$ mouse in saline, twice a week for 7 weeks and then once a week for 3 weeks) provided by InvivoGen and mice in groups 1 and 3 were given equivalent amount of saline. This dose of Rs-LPS was reported to be effective in blocking TLR4 by the previous studies (Baker et al. 1990, Hammad et al. 2009).

\section{Metabolic measurements}

Blood samples were obtained from jugular veins under the fasted condition and glucose level was determined using a Precision QID glucometer (MediSense, Inc., Bedford, MA, USA). Serum cholesterol and triglycerides were measured using Cholestech LDX Lipid monitoring System (Fisher Scientific, Pittsburgh PA, USA). Serum fatty acids were determined using the EnzyChrom free fatty acid kit (BioAssay Systems, Hayward, CA, USA).

Published by Bioscientifica Ltd. 


\section{En face analysis}

Mice were killed and aortas from heart to the iliac arteries were dissected out, soaked for $24 \mathrm{~h}$ in $4 \%$ paraformaldehyde for fixation, excised longitudinally and then stained with $0.5 \%$ of Sudan IV as described previously (Lloyd et al. 2011). After staining, the aortas were laid onto the sponge block surface with the intimal surface up and pined down using Minutien (Fine Science Tools, Inc., San Francisco, CA, USA). The images of the aortas were taken using an EPSON Perfection 2450 photo scanner and analyzed with Photoshop Software as described previously (Schuyler et al. 2011).

\section{Histological analysis of atherosclerotic lesions}

The tissues of aortic root were embedded in Tissue-Tek OCT compound (EMS, Hatfield, PA, USA), immediately frozen on dry ice, and stored at $-80^{\circ} \mathrm{C}$. Starting from the aortic root, cryosections with $6 \mu \mathrm{m}$ thickness were cut, and sections with a distance of $480 \mu \mathrm{m}$ were collected and mounted on slides. Slides were fixed in 10\% formalin for $10 \mathrm{~min}$, stained with Harris modified hematoxylin (Fisher Scientific) for $10 \mathrm{~min}$, and then rinsed in deionized water. Staining of hematoxylin was then developed in tap water for 5 min and differentiated in 1\% acid ethanol and blue staining for $50 \mathrm{~s}$. Slides were stained with eosin in Harleco 1\% alcohol solution (EMD Chemicals, Gibbstown, NJ, USA) for 2 min. Slides were placed in Coplin jars with 95\% ethanol three times for $5 \mathrm{~min}$ each and the process was then repeated with 100\% ethanol. Slides were further dehydrated in 99.5\% xylene (Sigma-Aldrich) and mounted in xylenebased Cytoseal-XYL mounting media (Fisher Scientific). Photomicrographs of tissue sections were taken using an Olympus BX53 digital microscope with Cellsens digital image software (Olympus American, Inc., Center Valley, PA, USA). The area of intima was expressed as the percentage of the total aortic area including intima, media, and lumen.

\section{Immunohistochemical analysis of protein expression}

Aortic roots were fixed in 10\% formalin for $10 \mathrm{~min}$ and frozen sections were made using a cryostat. Sections were rinsed in $0.01 \mathrm{M} \mathrm{PBS}, \mathrm{pH} 7.4$, and then incubated in $0.3 \% \mathrm{H}_{2} \mathrm{O}_{2} /$ methanol for $30 \mathrm{~min}$ to quench endogenous peroxidase. After being rinsed with $0.01 \mathrm{M}$ PBS, sections were incubated with 3\% normal serum in 0.01 M PBS for $1 \mathrm{~h}$ to block nonspecific binding. Sections were then blocked with avidin-biotin solution from the ABC Elite kit (Vector Laboratories, Burlingame, CA, USA) for $30 \mathrm{~min}$ and incubated with primary antibodies: rabbit anti-IL6 antibody (1:300; Abcam, Cambridge, MA, USA), goat antimatrix metalloproteinase-9 (MMP9) antibody (1:100; R\&D Systems), or rat anti-CD68 antibody (1:300; AbD Serotec, Raleigh, NC, USA) overnight at $4^{\circ} \mathrm{C}$. Sections were incubated with secondary biotinylated antibody (1:250) from the $\mathrm{ABC}$ Elite kit (Vector Laboratories) for $1 \mathrm{~h}$ and then the $\mathrm{ABC}$ reagent (Vector Laboratories) for $30 \mathrm{~min}$. Slides were rinsed in 0.01 M PBS and covered with diaminobenzidine peroxidase substrate solution from the Impack DAB kit (Vector Laboratories) for $2 \mathrm{~min}$ and then rinsed in water. Counterstaining was performed with hematoxylin. Slides were then dehydrated using increasing concentrations of ethanol and xylenes and mounted. Staining with normal IgG was used as a negative control. Images were taken and analyzed as described earlier for the histological analysis.

\section{Image analysis}

Images were analyzed with Photoshop Software (version 10; Adobe Systems). The method to use the 'Similar' feature to select a particular color staining on a digitized immunohistochemical image has previously been described in detail (Lloyd et al. 2011). Briefly, a standard was created by selecting an area of $0.5 \times 0.5 \mathrm{~cm}$ from a tissue section that had desired brown color from immunostaining. The cursor of the Magic Wand tool was clicked on the standard to make a selection and the area of the standard was highlighted. To specify how broad a range of color the Magic Wand tool should include in the selection, the Tolerance value in the Magic Wand Options palette was set to 100. Using the 'Similar' command, all the areas with the brown color that is similar to the standard on an image being determined were highlighted. The quantification was done using the Histogram command in the Image menu, which showed the pixels of the highlighted area. The extent of the positive immunostaining was presented as average pixels per cross section of atherosclerotic lesions.

\section{In situ zymography}

The unfixed frozen sections of aortic tissue were incubated for $24 \mathrm{~h}$ at $4{ }^{\circ} \mathrm{C}$ in a developing buffer (50 mM Tris, $\mathrm{pH} 7.4$, $150 \mathrm{mM} \mathrm{NaCl}, 5 \mathrm{mM} \mathrm{CaCl}$, and $0.2 \mathrm{mM}$ sodium azide) containing $250 \mu \mathrm{g} / \mathrm{ml}$ fluorescein-labeled DQ-Gelatin (Invitrogen) with Tris-borate buffer containing 1\% agarose. Sections were rinsed three times with PBS, mounted, and examined with an Olympus BX53 fluorescence microscope.

Published by Bioscientifica Ltd. 


\section{Transfection and luciferase activity assay}

U937 cells were transfected with $0.5 \mu \mathrm{g}$ NF- $\kappa \mathrm{B}$ or AP-1 Cignal reporter firefly luciferase constructs (Qiagen, Inc.) using Fugene HD as the transfection reagent (Roche Diagnostics Corp.) for $20 \mathrm{~h}$. The constitutively expressing renilla luciferase constructs were used as control. The cells were then treated with $100 \mathrm{ng} / \mathrm{ml}$ LPS in the absence or presence of $500 \mathrm{ng} / \mathrm{ml}$ Rs-LPS for $12 \mathrm{~h}$. After the treatment, the cells were rinsed with cold PBS and lysed with the lysis buffer from the dual-luciferase reporter assay system (Promega). Both firefly and renilla luciferase levels were measured in a luminometer using the dual-luciferase reporter assay reagents (Promega). The firefly luciferase levels were normalized to the renilla luciferase levels.

\section{Statistical analysis}

Data were presented as mean \pm s.D. Student's $t$-tests were performed to determine the statistical significance of differences of intimal lesion size and protein expression among different experimental groups. A value of $P<0.05$ was considered significant.

\section{Results}

\section{Rs-LPS is a potent TLR4 antagonist}

To confirm that Rs-LPS is a potent TLR4 antagonist, HAECs were stimulated with $100 \mathrm{ng} / \mathrm{ml}$ LPS in the absence or presence of Rs-LPS or TLR4 neutralizing antibody for $24 \mathrm{~h}$, and IL6 in the medium was then quantified. Results showed that while $10 \mu \mathrm{g} / \mathrm{ml}$ TLR4 neutralizing antibody blocked LPS-stimulated IL6 secretion as expected, $100 \mathrm{ng} / \mathrm{ml}$ Rs-LPS also completely abolished the stimulatory effect of LPS (Fig. 1A). In addition to HAECs, Rs-LPS also effectively antagonized LPS-stimulated MMP1 and IL6 secretion by human U937 mononuclear cells in a concentration-dependent manner (Fig. 1B and C). The $\mathrm{IC}_{50}$ for Rs-LPS to inhibit LPS (100 ng/ml)-stimulated IL6 secretion is between 10 and $50 \mathrm{ng} / \mathrm{ml}$, indicating that Rs-LPS is a potent TLR4 antagonist.

\section{Rs-LPS reduces cholesterol and triglycerides in nondiabetic mice}

In this study, diabetes was induced by STZ in $\mathrm{Apoe}^{-/-}$mice and blood glucose was determined 1, 2, 3, and 3.5 months after STZ treatment. Results showed that fasting glucose level was increased significantly at 1 month and stabilized
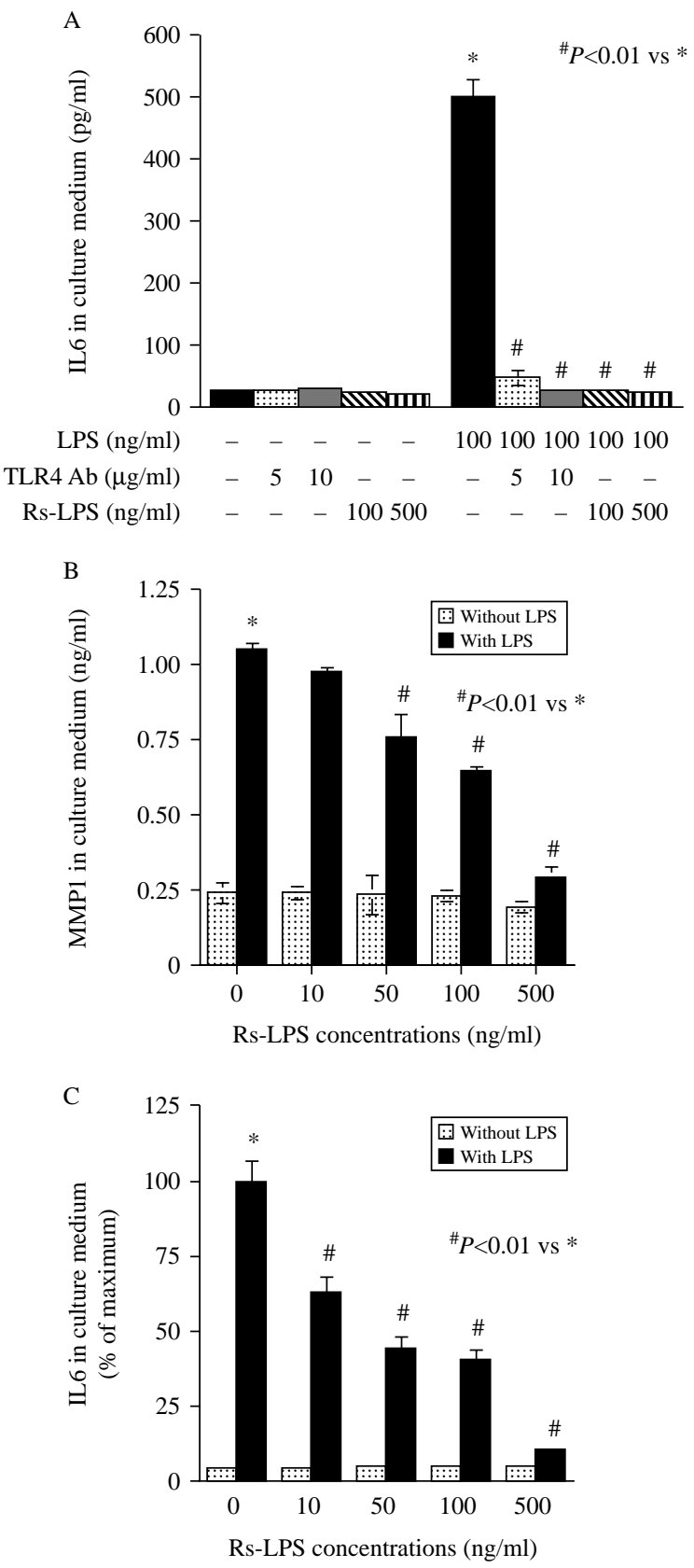

Figure 1

The effect of Rs-LPS on LPS-stimulated IL6 secretion by HAECs (A) and U937 mononuclear cells (B). (A) HAECs were treated with $100 \mathrm{ng} / \mathrm{ml}$ LPS in the absence or presence of Rs-LPS (100 or $500 \mathrm{ng} / \mathrm{ml}$ ) or TLR4 neutralizing antibodies ( 5 or $10 \mu \mathrm{g} / \mathrm{ml}$ ) for $24 \mathrm{~h}$. After the treatment, IL6 in culture medium was quantified using ELISA. (B and C) U937 cells were treated with $100 \mathrm{ng} / \mathrm{ml}$ LPS in the absence or presence of different concentrations of Rs-LPS (10-500 ng/ml) for $24 \mathrm{~h}$. After the treatment, MMP1 (B) and IL6 (C) in culture medium were quantified using ELISA. In (C), IL6 released by LPS-stimulated U937 cells in the absence of Rs-LPS was designated as $100 \%$ (maximum) and IL6 released by cells in other groups was presented as percentage of the maximum. The data (mean \pm s.D.) were representative of two experiments with similar results. 
after 2 months, and Rs-LPS treatment had no significant effect on glucose levels in both nondiabetic and diabetic mice (Fig. 2A). At the end of the study, body weight and serum lipids were determined. Data showed that the average body weight of diabetic mice was about $17-23 \%$ lower than that of nondiabetic mice (Fig. 2B), which is consistent with our previous report (Ta et al. 2011), and Rs-LPS treatment did not affect body weight significantly (Fig. 2B). Interestingly, Rs-LPS treatment reduced total cholesterol by $25 \%$ and triglycerides by $44 \%$ in nondiabetic mice (Fig. 2C and D). By contrast, no inhibitory effect of Rs-LPS on cholesterol and triglyceride levels was observed in diabetic Apoe ${ }^{-/-}$mice. Similarly, Rs-LPS also marginally reduced serum fatty acid level in nondiabetic mice $(P=0.053)$ but not in diabetic mice (Fig. $2 \mathrm{E})$.
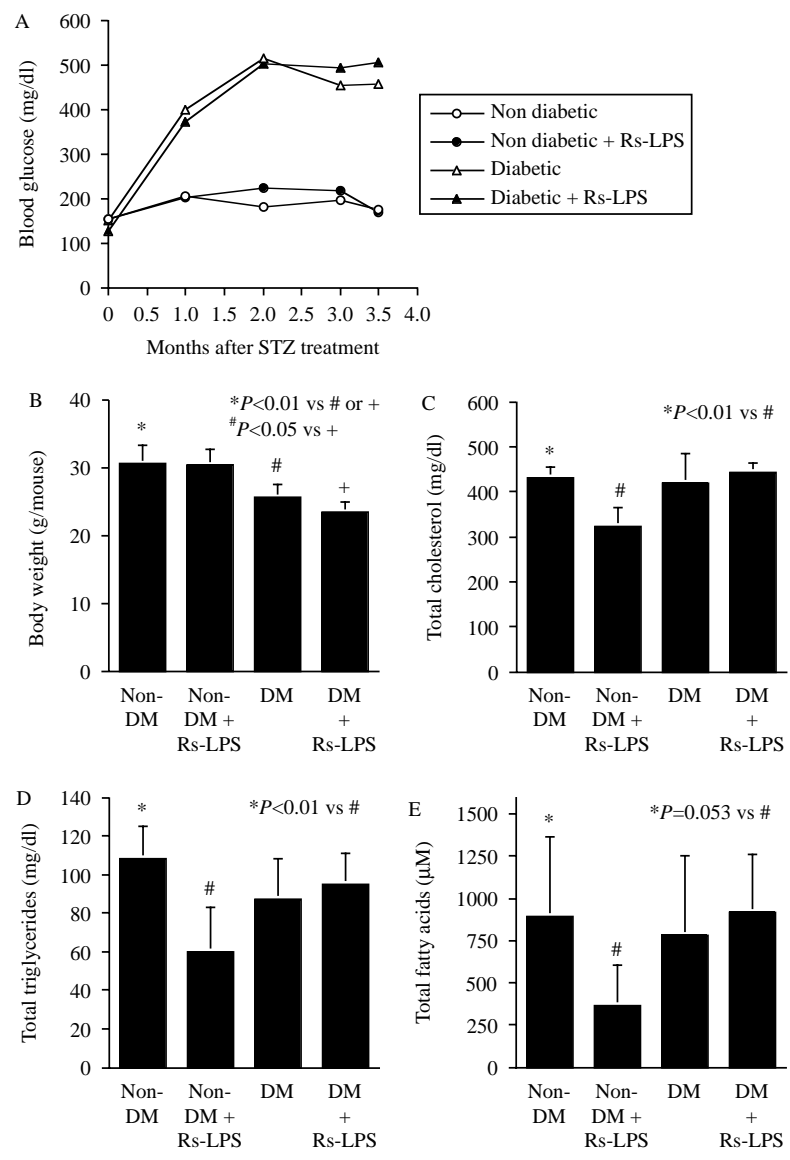

Figure 2

The effects of Rs-LPS on metabolic parameters. (A) Blood glucose was determined 1, 2, 3, and 3.5 months after STZ treatment. (B, C and D) Metabolic parameters including body weight (B), serum total cholesterol (C), triglycerides (D), and free fatty acids (E) were determined at the end of the study. The data presented are mean \pm s.D. $(n=5,7,9$, and 8 in the groups of non-DM, non-DM+Rs-LPS, DM, and DM + Rs-LPS respectively).

\section{Rs-LPS inhibits atherosclerosis in diabetic $A p o e^{-/-}$mice}

Two approaches were taken to determine the effect of Rs-LPS treatment on atherosclerosis: 1) analysis of en face atherosclerotic lesions in aortas and 2) histological analysis of atherosclerotic lesions in the cross section of aortic roots. As shown in Fig. 3A and B, the en face area of aortas with positive Sudan IV staining was increased significantly in diabetic mice when compared with that in nondiabetic mice. Although the lesion area appeared to be reduced by Rs-LPS treatment in nondiabetic mice, the difference did not reach statistical significance. However, Rs-LPS treatment in diabetic mice significantly decreased atherosclerotic lesions (Fig. 3A and B). Consistent with the observations from the analysis of en face atherosclerotic lesions in aortas, the histological analysis of the intimal lesions on cross sections of the aortic roots also showed that Rs-LPS reduced atherosclerotic lesions significantly in diabetic but not in nondiabetic mice (Fig. 3C and D).

\section{Rs-LPS inhibits IL6 and MMP9 expression in athero- sclerotic plaques in diabetic Apoe $^{-/-}$mice}

To determine the effect of Rs-LPS on vascular inflammation, we focused on IL6 and MMP9 as both of them have been shown to play an important role in atherosclerosis (Hamirani et al. 2008). Results showed that the expression of IL6 (Fig. 4A and B) and MMP9 (Fig. 4C and D) in atherosclerotic plaques was higher in diabetic mice than that in nondiabetic mice, and Rs-LPS treatment led to a significantly decreased IL6 and MMP9 expression in diabetic but not in nondiabetic mice. To determine whether MMP9 detected in atherosclerotic plaques has gelatinase activity, in situ zymography using fluoresceinlabeled gelatin was performed. Results showed that the core of the atherosclerotic plaques had both high MMP9 expression and gelatinase activity (Fig. 4E). The images also suggest that MMPs other than MMP9 had gelatinase activity, as gelatinase activity was also observed in the shoulder region of atherosclerotic plaque where little MMP9 protein was detected (Fig. 4E).

\section{Rs-LPS reduces monocyte/macrophage content in atherosclerotic lesions in diabetic Apoe $^{-/-}$mice}

Monocytes and macrophages in atherosclerotic plaques were detected by immunostaining. Results showed that diabetes increased monocyte/macrophage content significantly and Rs-LPS treatment reduced the content in

Published by Bioscientifica Ltd. 


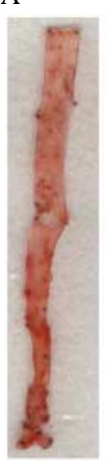

Non-DM

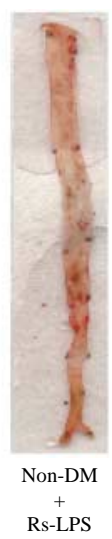

$\stackrel{+}{\stackrel{+}{R s-L P S}}$

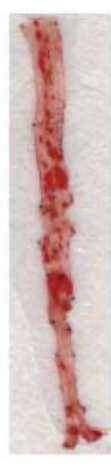

DM

$\stackrel{+}{\stackrel{+}{R s-L P S}}$

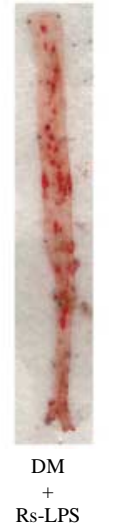

B
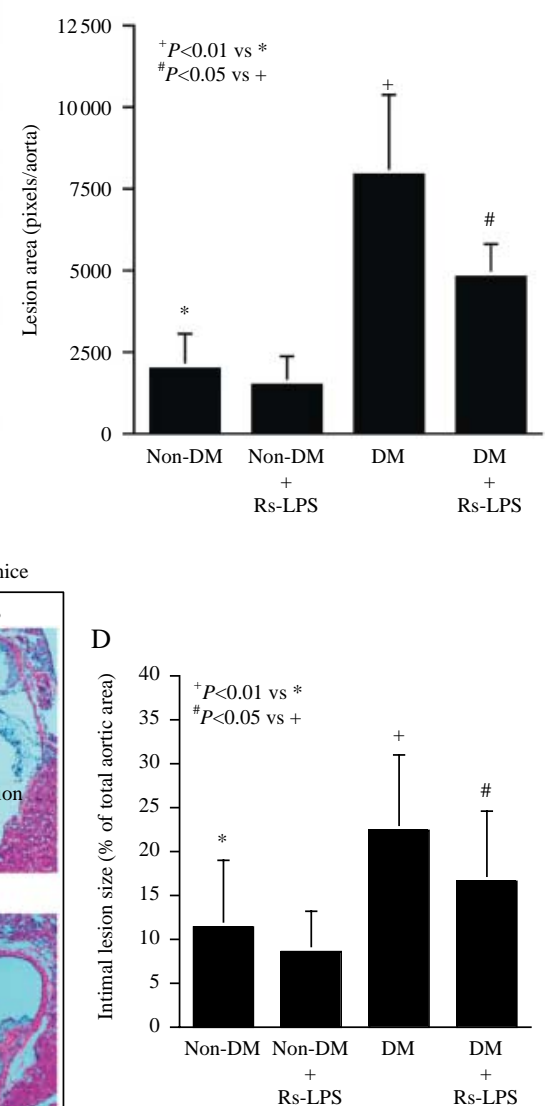

Figure 3

Reduction of atherosclerotic lesions in diabetic $\mathrm{Apoe}^{-1-}$ mice treated with Rs-LPS. (A) Sudan IV staining of en face aortas from four groups: nondiabetic mice (non-DM), nondiabetic mice treated with Rs-LPS (nonDM + Rs-LPS), diabetic mice (DM), and diabetic mice treated with Rs-LPS (DM+Rs-LPS). (B) Quantification of area with positive staining of the en face aortas ( $n=6,7,9$, and 8 for groups of non-DM, non-DM + Rs-LPS, DM, and DM + Rs-LPS respectively). (C) Representative photomicrographs

diabetic mice (Fig. 5A and B). By contrast, Rs-LPS treatment had no significant inhibition on monocyte/macrophage content in nondiabetic mice.

\section{Inhibition of LPS stimulates NF- $\kappa$ B transcriptional activity by Rs-LPS in mononuclear cells}

To better understand the mechanisms by which Rs-LPS inhibited LPS-induced vascular inflammation, we further determined the effect of Rs-LPS on LPS-stimulated NF- $\kappa$ B transcriptional activity in U937 mononuclear cells. Results showed that LPS markedly stimulated NF- $\mathrm{B}$ activity and Rs-LPS inhibited LPS-stimulated NF- $\kappa$ B activity by $90 \%$ (Fig. 6A). Furthermore, Bay117085, a specific inhibitor of atherosclerotic lesions in the aortic roots of non-diabetic or diabetic Apoe $^{-/-}$mice treated with or without Rs-LPS. Magnification: $4 \times$. (D) Quantification of intimal lesion area of atherosclerotic plaques in the aortic roots $(n=6,7,9$, and 8 for groups of non-DM, non-DM + Rs-LPS, DM, and DM + Rs-LPS respectively). The area of the intimal lesions was presented as percentage of the total aortic area.

of NF-кB (Ni et al. 2001), inhibited LPS-stimulated IL6 secretion in a concentration-dependent manner (Fig. 6B), indicating an essential role of NF- $\kappa \mathrm{B}$ in LPS-induced inflammatory response in mononuclear cells.

\section{Discussion}

The nontoxicity of Rs-LPS in mice and rabbits was first reported by Strittmatter et al. (1983). It was shown that over a range of $10-1000 \mathrm{ng} / \mathrm{ml}$, Rs-LPS did not induce inflammatory cytokine TNF $\alpha$ in the RAW264.7 macrophages (Qureshi et al. 1991). To understand the mechanisms for Rs-LPS's nontoxicity, analysis of chemical structure showed that Rs-LPS is different from pathological

Published by Bioscientifica Ltd 
A
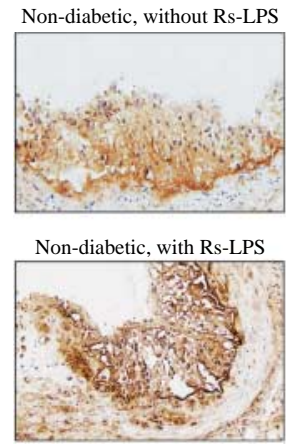

C

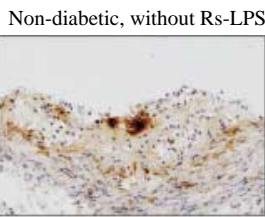

Non-diabetic, with Rs-LPS
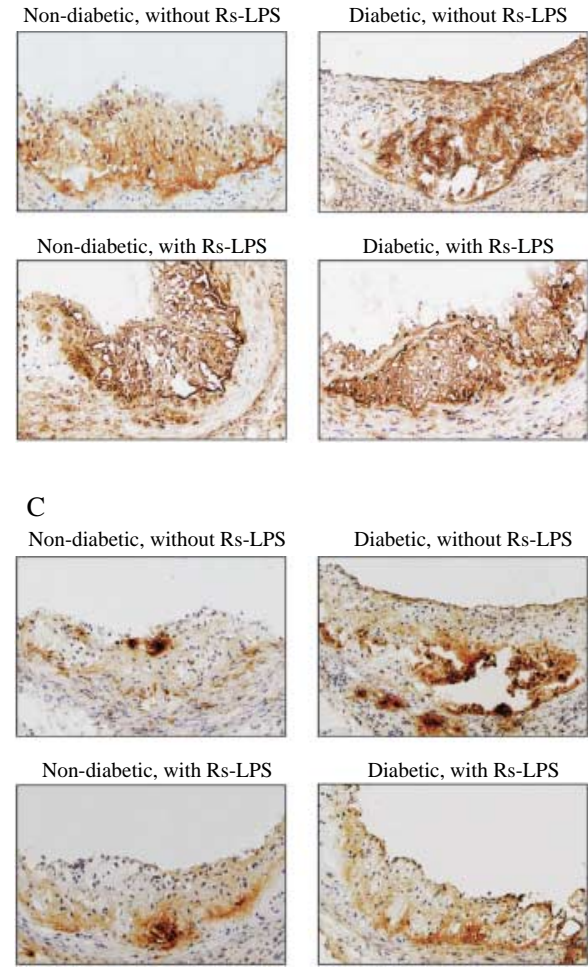

Diabetic, with Rs-LPS

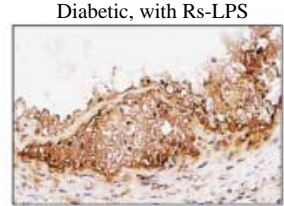

Diabetic, without Rs-LPS

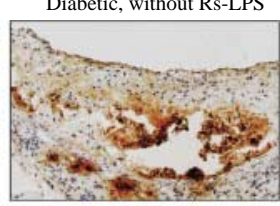

Diabetic, with Rs-LPS

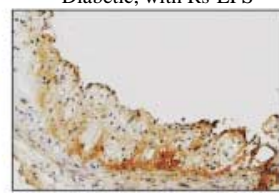

B

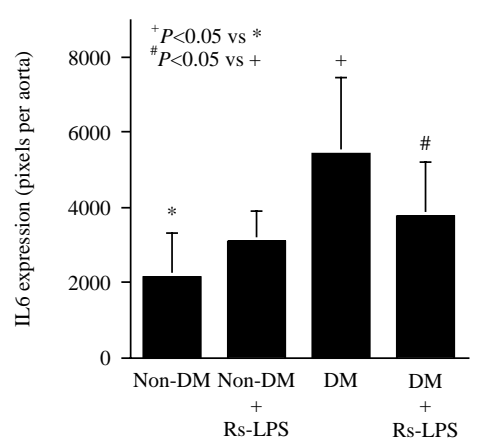

D

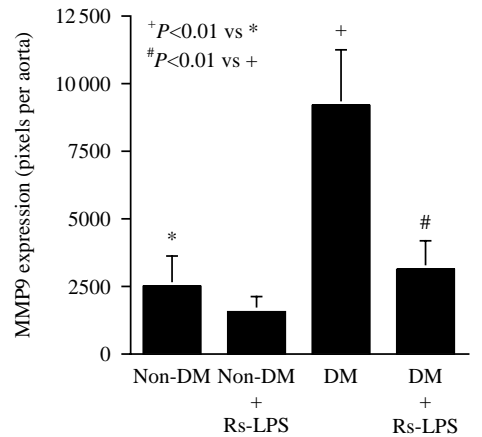

E
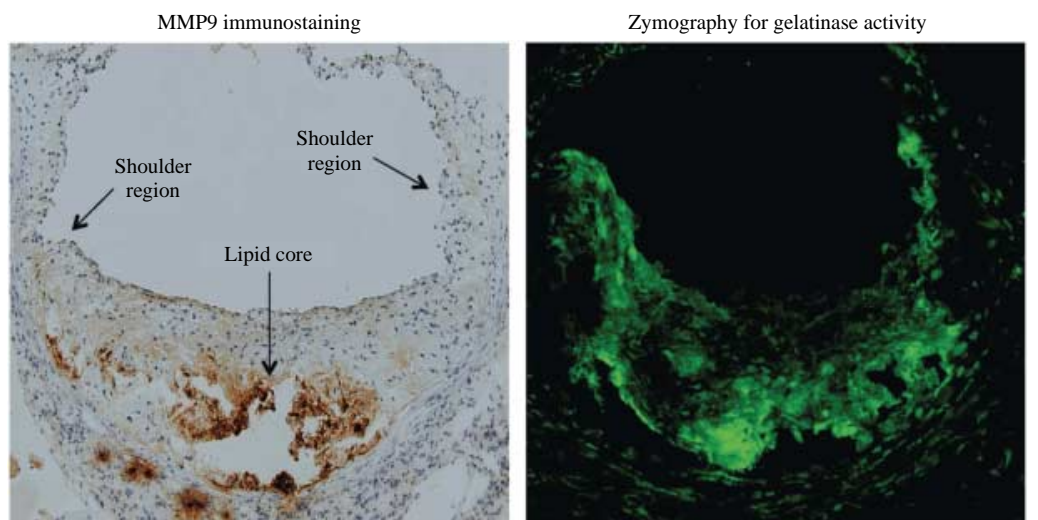

Figure 4

Inhibition by Rs-LPS of IL6 and MMP9 expression in atherosclerotic lesions of diabetic Apoe ${ }^{-1-}$ mice. Mice were killed after the treatment with Rs-LPS and aortic roots were dissected and processed for frozen sections and immunohistochemical analysis of IL6 and MMP9 expression. (A) Immunohistochemistry analysis of IL6 expression. Magnification: $10 \times$

(B) Quantification of IL6 protein expression. (C) Immunohistochemistry analysis of MMP9 expression. (D) Quantification of MMP9 protein

LPS in number and nature of fatty acyl groups in the lipid A moiety (Kaltashov et al. 1997). Further study showed that Rs-LPS is capable of antagonizing TLR4 because it competes with pathological LPS for the same binding site expression. IL6 and MMP9 detected by immunostaining were quantified as described in the Materials and Methods section. The animal numbers in the groups are same as those in Fig. 3. (E) Gelatinase activity in atherosclerotic lesions detected by in situ zymography. MMP9 immunostaining of aortic cross section from a diabetic mouse. In situ zymograph to detect gelatinase activity (green fluorescence) of aortic tissue from the same diabetic mouse.

on MD-2, a TLR4 co-receptor that confers LPS responsiveness (Visintin et al. 2005). In recent years, studies have well demonstrated that Rs-LPS effectively and specifically blocks a number of TLR4-mediated pathological effects

Published by Bioscientifica Ltd 

Non diabetic, without Rs-LPS

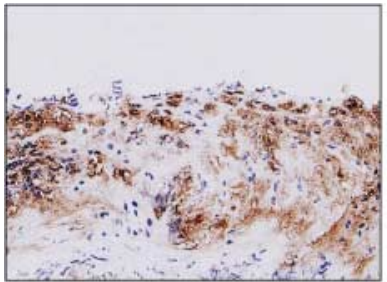

Non diabetic, with Rs-LPS

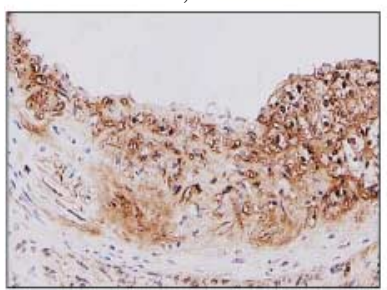

Diabetic, without Rs-LPS

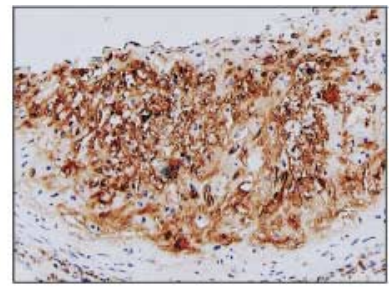

Diabetic, with Rs-LPS

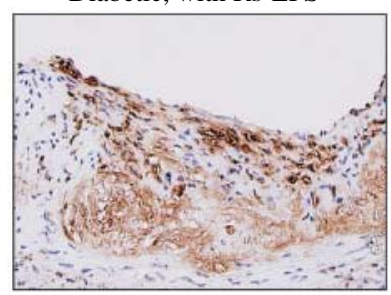

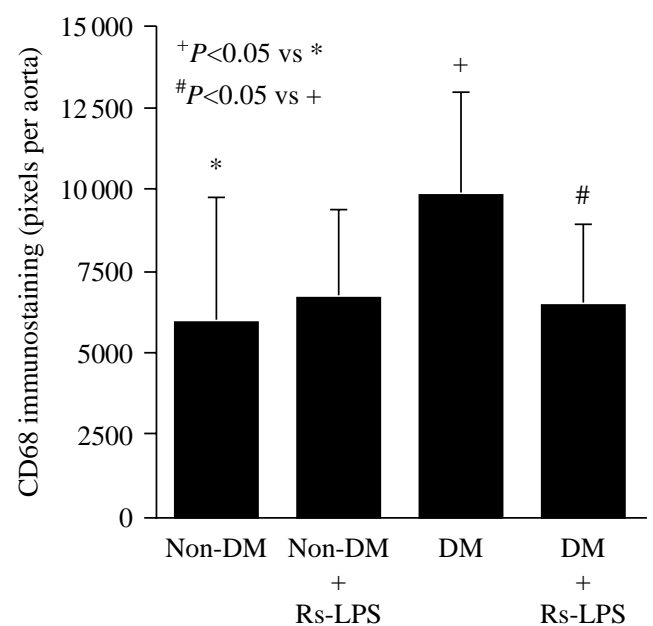

\section{Figure 5}

Inhibition by Rs-LPS on monocyte/macrophage accumulation in atherosclerotic lesions of diabetic Apoe ${ }^{-1-}$ mice. Mouse monocytes/macrophages were detected using anti-CD68 antibody. (A) Representative photomicrographs of CD68 immunostaining of atherosclerotic plaques.

(Baker et al. 1990, Kirkland et al. 1991, Aida et al. 1995, Hammad et al. 2009, Hutchinson et al. 2010).

In this study, we used Rs-LPS to test our hypothesis that TLR4 blockade attenuated atherogenesis in both nondiabetic and diabetic animal models. We focused on the effect of TLR4 blockade on the early-stage atherosclerosis in $A p o e^{-/-}$mice by starting administration of Rs-LPS at age of 14 weeks for 10 weeks of treatment. InConsistent with our previous reports (Schuyler et al. 2011, Ta et al. 2011), this study showed that diabetes accelerated the formation of atherosclerotic lesions in $A p o e^{-/-}$mice. To understand the mechanisms involved in accelerated atherosclerosis in diabetes, increasing studies have indicated that hyperglycemia promotes a pro-inflammatory state, which plays a central role in diabetes-associated atherosclerosis (Theuma \& Fonseca 2003). In agreement with this notion, our present study showed that diabetic Apoe $e^{-/-}$mice have increased expression of IL6 and MMP9 and content of infiltrated monocytes/macrophages in atherosclerotic lesions when compared with nondiabetic Apoe $e^{-/-}$mice. As TLR4 plays an important role in inflammation that is responsible for not only atherosclerosis but also diabetes (Bjorkbacka et al. 2004, Michelsen et al. 2004, Zipris 2010, Devaraj et al. 2011, Grieco et al. 2011), it is rational to postulate that TLR4 blockade with Rs-LPS in diabetic $A p o e^{-/-}$mice would have higher impact than that in nondiabetic $A p o e^{-/-}$
(B) Quantification of CD68 immunostaining in atherosclerotic plaques. The intensity of the staining was presented as pixels per aorta. The animal numbers in the groups are same as those in Fig. 3.

mice on inflammation-related atherosclerosis. Indeed, the current study showed that Rs-LPS significantly reduced atherosclerotic lesions in diabetic Apoe $e^{-/-}$mice.

In addition to the observations that Rs-LPS attenuated early-stage atherosclerosis in diabetic mice, another intriguing finding from the current study is that Rs-LPS reduced serum cholesterol and triglyceride levels in nondiabetic Apoe $e^{-/-}$mice. This finding suggests the presence of a TLR4-mediated regulatory pathway in cholesterol and triglyceride metabolism in $A p o e^{-/-}$mice. In fact, the involvement of a TLR4-mediated pathway in cholesterol and triglyceride biosynthesis in hepatocytes has been reported previously (Victorov et al. 1989, Aspichueta et al. 2006). Victorov et al. (1989) have shown that LPS increased intracellular content of free cholesterol, esterified cholesterol, and triglycerides by $30-40 \%$ in the primary culture of rabbit hepatocytes. Aspichueta et al. (2006) also reported that rats treated with LPS had increased levels of VLDL-containing apoB, triglyceride, and cholesterol. Our present study demonstrated for the first time that TLR4 blockade is effective in lowering cholesterol and triglyceride levels. Interestingly, Higashimori et al. (2011) reported that TLR4 deficiency in $A$ poe $e^{-1-}$ mice was not associated with reduced serum cholesterol and triglycerides. To explain the controversy between their report and our current study, we believe that as TLR4 deficiency in these mice is inborn,

Published by Bioscientifica Ltd 

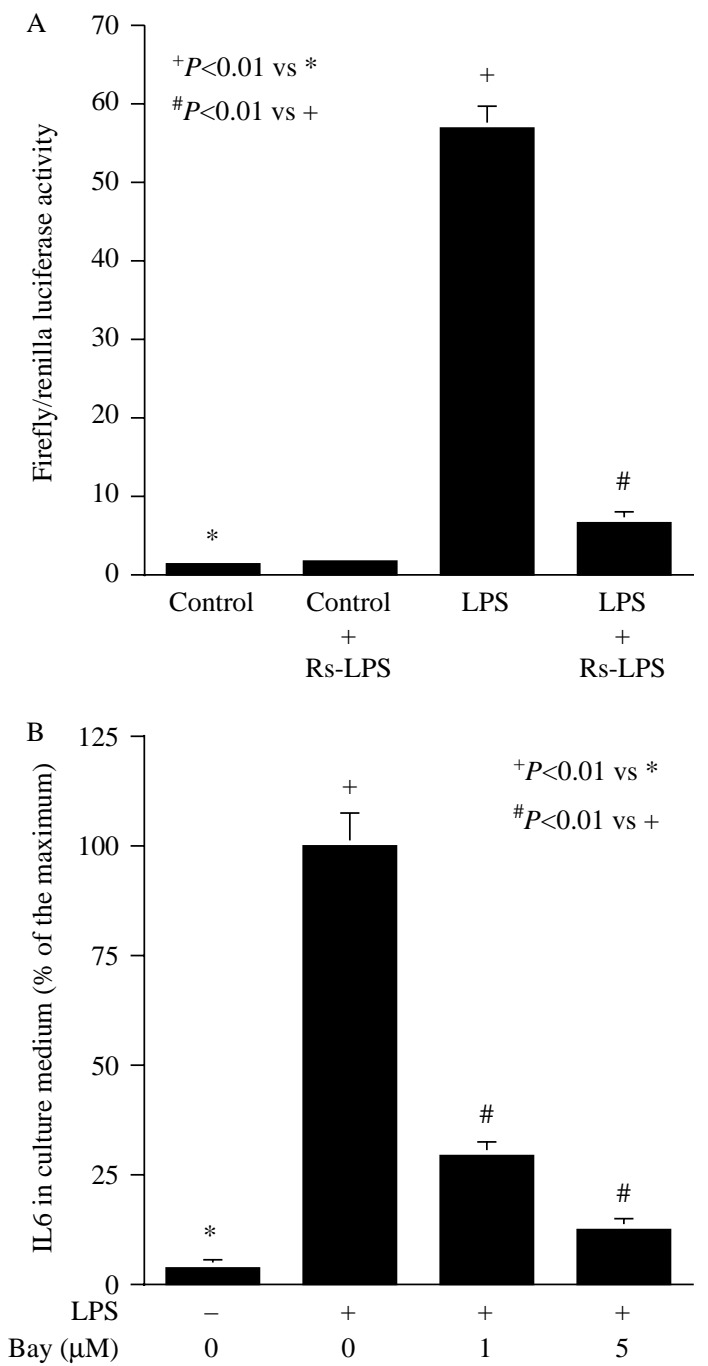

\section{Figure 6}

Inhibition by Rs-LPS on LPS-stimulated NF-KB transcriptional activity in U937 mononuclear cells. (A) U937 cells transfected with NF-KB promoterluciferase reporter constructs were treated with or without $100 \mathrm{ng} / \mathrm{ml}$ LPS in the absence or presence of $500 \mathrm{ng} / \mathrm{ml} \mathrm{Rs-LPS} \mathrm{for} 12 \mathrm{~h}$. After the treatment, cells were lysed and firefly luciferase activity was determined and normalized to renilla luciferase activity. (B) U937 cells were treated with $100 \mathrm{ng} / \mathrm{ml}$ LPS in the absence or presence of 1 or $5 \mu \mathrm{M}$ Bay 117085 (Bay) for $24 \mathrm{~h}$ and IL6 in culture medium was quantified using ELISA. The amount of IL6 released by cells treated with LPS in the absence of Bay 117085 was designated as $100 \%$ (maximum). IL6 released by cells in other groups was presented as percentage of the maximum. The data presented are the representative from two experiments with the similar results.

the TLR4-mediated regulation of lipid metabolism in TLR4-knockout mice is compensated by other mechanisms. In our current study, however, TLR4 had been functioning in mice before its blockade with Rs-LPS. Thus, TLR4-mediated regulatory pathways on lipid metabolism are interrupted abruptly and cells are not able to compensate for this. A recent study showed that TLR4 deficiency in LDL receptor-deficient mice fed a diabetogenic diet was associated with improved plasma cholesterol and triglyceride levels (Ding et al. 2012), suggesting that TLR4 deficiency reduces obesity-induced hyperlipidemia in LDL receptor-deficient mice. These findings are consistent with the results from our present study and underscored an essential role of TLR4 signaling in hepatic lipoprotein metabolism.

In our present study, no LPS or gram-negative bacteria were given to mice. Therefore, it is likely that endogenous ligands were responsible for stimulating TLR4-dependent pathways for cholesterol and triglyceride metabolism. Although the particular endogenous TLR4 ligands that are involved in cholesterol and triglyceride metabolism in Apoe $^{-1-}$ mice remain unknown at this time, endogenous TLR4 ligands such as mmLDL (Miller et al. 2003, 2005) have been reported. Obviously, more investigations are warranted to identify endogenous TLR4 ligands involved in alteration of cholesterol and triglyceride metabolism.

Interestingly, our results showed that while Rs-LPS reduced serum cholesterol and triglycerides in nondiabetic $A p o e^{-/-}$mice, it failed to do so in diabetic $A p o e^{-1-}$ mice, suggesting that factor(s) related to hyperglycemia in diabetic mice may abolish the inhibitory effect of Rs-LPS on cholesterol and triglyceride metabolism in liver. We hypothesize that some hyperglycemia-related factors are effective on hepatocytes to abolish the inhibitory effect of Rs-LPS on lipid metabolisms, but ineffective on vascular cells to neutralize the effect of Rs-LPS on vascular inflammation. Therefore, Rs-LPS was capable of inhibiting atherogenesis but failed to reduce serum lipid levels in diabetic mice. Further investigations are necessary to identify the factors that specifically neutralize the effect of Rs-LPS in hepatocytes.

Our results showed that Rs-LPS treatment did not change serum glucose, cholesterol, and triglycerides in diabetic $A p o e^{-/-}$mice but inhibited the expression of IL6 and MMP9, two key molecules involved in inflammation, and reduced monocyte/macrophage accumulation in atherosclerotic lesions. Thus, it is strongly suggested that Rs-LPS treatment reduced atherosclerosis by inhibiting vascular inflammation. Given that TLR4 is a receptor for the innate immune response, this study underscored the important role of the innate immune response in diabetesassociated atherosclerosis.

Several TLR4 antagonists have been developed and applied to treatment of sepsis and other diseases in animal models (Fort et al. 2005, Sun \& Pearlman 2009). For example, it has been shown that treatment with CRS-526,

Published by Bioscientifica Ltd. 
a lipid A-mimetic, inhibits the development of moderateto-severe disease in two mouse models of colonic inflammation (Fort et al. 2005). Another TLR4 antagonist, Eritoran tetrasodium (E5564), has been effective in the treatment of Pseudomonas aeruginosa-induced corneal inflammation (Sun \& Pearlman 2009). In recent years, TLR4 antagonists have been successfully applied in the treatment of several infection-unrelated diseases in animal models such as myocardial injury induced by chronic stress (Wang et al. 2011). Clearly, TLR4 blockade with TLR4 antagonists was effective in the treatment of various inflammation-associated diseases in animal models.

In conclusion, this study has shown for the first time that the TLR4 antagonist Rs-LPS is effective to reduce vascular inflammation and early-stage atherosclerosis in diabetic mice. The findings from this study suggest that TLR4 is a potential target for anti-inflammatory therapy to reduce cardiovascular complications in diabetic patients. While the findings from this study are interesting, it is noteworthy that there are some limitations in this study. First, the animal model employed in this study is the type 1 diabetic mouse model. Thus, the findings from this study may be different from those from the study using mouse models for type 2 diabetes. Second, our in vitro investigations in this study focused on mononuclear cells. Given the crucial role of smooth muscle cell (SMC) proliferation in atherogenesis, it is important to characterize the effect of Rs-LPS on vascular SMC proliferation to better understand the effect of Rs-LPS on atherogenesis.

\section{Declaration of interest}

The authors declare that there is no conflict of interest that could be perceived as prejudicing the impartiality of the research reported.

\section{Funding}

This work was supported by Merit Review Grant from the Biomedical Laboratory Research and Development Program of the Department of Veterans Affairs and by NIH grant RO1 DE016353 (to Y H).

\section{References}

Aida Y, Kusumoto K, Nakatomi K, Takada H, Pabst MJ \& Maeda K 1995 An analogue of lipid A and LPS from Rhodobacter sphaeroides inhibits neutrophil responses to LPS by blocking receptor recognition of LPS and by depleting LPS-binding protein in plasma. Journal of Leukocyte Biology 58 675-682.

Aspichueta P, Perez-Agote B, Perez S, Ochoa B \& Fresnedo O 2006 Impaired response of VLDL lipid and apoB secretion to endotoxin in the fasted rat liver. Journal of Endotoxin Research 12 181-192. (doi:10.1179/ 096805106X102174)
Baker PJ, Taylor CE, Stashak PW, Fauntleroy MB, Haslov K, Qureshi N \& Takayama K 1990 Inactivation of suppressor T cell activity by the nontoxic lipopolysaccharide of Rhodopseudomonas sphaeroides. Infection and Immunity 58 2862-2868.

Bjorkbacka H, Kunjathoor VV, Moore KJ, Koehn S, Ordija CM, Lee MA, Means T, Halmen K, Luster AD, Golenbock DT et al. 2004 Reduced atherosclerosis in MyD88-null mice links elevated serum cholesterol levels to activation of innate immunity signaling pathways. Nature Medicine 10 416-421. (doi:10.1038/nm1008)

Devaraj S, Tobias P \& Jialal I 2011 Knockout of toll-like receptor-4 attenuates the pro-inflammatory state of diabetes. Cytokine 55 441-445. (doi:10.1016/j.cyto.2011.03.023)

Ding Y, Subramanian S, Montes VN, Goodspeed L, Wang S, Han C, Teresa AS III, Kim J, O’Brien KD \& Chait A 2012 Toll-like receptor 4 deficiency decreases atherosclerosis but does not protect against inflammation in obese low-density lipoprotein receptor-deficient mice. Arteriosclerosis, Thrombosis, and Vascular Biology 32 1596-1604. (doi:10.1161/ATVBAHA.112.249847)

Fort MM, Mozaffarian A, Stover AG, Correia Jda S, Johnson DA, Crane RT, Ulevitch RJ, Persing DH, Bielefeldt-Ohmann H, Probst P et al. 2005 A synthetic TLR4 antagonist has anti-inflammatory effects in two murine models of inflammatory bowel disease. Journal of Immunology 174 6416-6423.

Goldberg IJ, Isaacs A, Sehayek E, Breslow JL \& Huang LS 2004 Effects of streptozotocin-induced diabetes in apolipoprotein AI deficient mice. Atherosclerosis 172 47-53. (doi:10.1016/j.atherosclerosis.2003.09.014)

Grieco FA, Vendrame F, Spagnuolo I \& Dotta F 2011 Innate immunity and the pathogenesis of type 1 diabetes. Seminars in Immunopathology 33 57-66. (doi:10.1007/s00281-010-0206-z)

Hamirani YS, Pandey S, Rivera JJ, Ndumele C, Budoff MJ, Blumenthal RS \& Nasir K 2008 Markers of inflammation and coronary artery calcification: a systematic review. Atherosclerosis 201 1-7. (doi:10.1016/ j.atherosclerosis.2008.04.045)

Hammad H, Chieppa M, Perros F, Willart MA, Germain RN \& Lambrecht BN 2009 House dust mite allergen induces asthma via toll-like receptor 4 triggering of airway structural cells. Nature Medicine 15 410-416. (doi:10.1038/nm.1946)

Higashimori M, Tatro JB, Moore KJ, Mendelsohn ME, Galper JB \& Beasley D 2011 Role of toll-like receptor 4 in intimal foam cell accumulation in apolipoprotein E-deficient mice. Arteriosclerosis, Thrombosis, and Vascular Biology 31 50-57. (doi:10.1161/ATVBAHA.110.210971)

Hutchinson MR, Zhang Y, Shridhar M, Evans JH, Buchanan MM, Zhao TX, Slivka PF, Coats BD, Rezvani N, Wieseler J et al. 2010 Evidence that opioids may have toll-like receptor 4 and MD-2 effects. Brain, Behavior, and Immunity 24 83-95. (doi:10.1016/j.bbi.2009.08.004)

Kaltashov IA, Doroshenko V, Cotter RJ, Takayama K \& Qureshi N 1997 Confirmation of the structure of lipid A derived from the lipopolysaccharide of Rhodobacter sphaeroides by a combination of MALDI, LSIMS, and tandem mass spectrometry. Analytical Chemistry 69 2317-2322. (doi:10.1021/ac9612943)

Kanter JE, Kramer F, Barnhart S, Averill MM, Vivekanandan-Giri A, Vickery T, Li LO, Becker L, Yuan W, Chait A et al. 2012 Diabetes promotes an inflammatory macrophage phenotype and atherosclerosis through acyl-CoA synthetase 1. PNAS 109 E715-E724. (doi:10.1073/ pnas.1111600109)

Kirkland TN, Qureshi N \& Takayama K 1991 Diphosphoryl lipid A derived from lipopolysaccharide (LPS) of Rhodopseudomonas sphaeroides inhibits activation of 70Z/3 cells by LPS. Infection and Immunity 59 131-136.

Lloyd DJ, Helmering J, Kaufman SA, Turk J, Silva M, Vasquez S, Weinstein D, Johnston B, Hale C \& Veniant MM 2011 A volumetric method for quantifying atherosclerosis in mice by using microCT: comparison to en face. PLOS ONE 6 e18800. (doi:10.1371/journal.pone.0018800)

Mendall MA, Carrington D, Strachan D, Patel P, Molineaux N, Levi J, Toosey T, Camm AJ \& Northfield TC 1995 Chlamydia pneumoniae: risk factors for seropositivity and association with coronary heart disease. Journal of Infection 30 121-128. (doi:10.1016/S0163-4453(95)80006-9) 
Michelsen KS, Wong MH, Shah PK, Zhang W, Yano J, Doherty TM, Akira S, Rajavashisth TB \& Arditi M 2004 Lack of toll-like receptor 4 or myeloid differentiation factor 88 reduces atherosclerosis and alters plaque phenotype in mice deficient in apolipoprotein E. PNAS 101 10679-10684. (doi:10.1073/pnas.0403249101)

Miller YI, Viriyakosol S, Binder CJ, Feramisco JR, Kirkland TN \& Witztum JL 2003 Minimally modified LDL binds to CD14, induces macrophage spreading via TLR4/MD-2, and inhibits phagocytosis of apoptotic cells. Journal of Biological Chemistry 278 1561-1568. (doi:10.1074/ jbc.M209634200)

Miller YI, Viriyakosol S, Worrall DS, Boullier A, Butler S \& Witztum JL 2005 Toll-like receptor 4-dependent and -independent cytokine secretion induced by minimally oxidized low-density lipoprotein in macrophages. Arteriosclerosis, Thrombosis, and Vascular Biology 25 1213-1219. (doi:10.1161/01.ATV.0000159891.73193.31)

Ni H, Ergin M, Huang Q, Qin JZ, Amin HM, Martinez RL, Saeed S, Barton K \& Alkan S 2001 Analysis of expression of nuclear factor $\kappa \mathrm{B}$ (NF-kB) in multiple myeloma: downregulation of NF- $\mathrm{kB}$ induces apoptosis. British Journal of Haematology 115 279-286. (doi:10.1046/j.1365-2141.2001. 03102.x)

Qureshi N, Takayama K, Meyer KC, Kirkland TN, Bush CA, Chen L, Wang R \& Cotter RJ 1991 Chemical reduction of 3-oxo and unsaturated groups in fatty acids of diphosphoryl lipid A from the lipopolysaccharide of Rhodopseudomonas sphaeroides. Comparison of biological properties before and after reduction. Journal of Biological Chemistry 266 6532-6538.

Schuyler CA, Ta NN, Li Y, Lopes-Virella MF \& Huang Y 2011 Insulin treatment attenuates diabetes-increased atherosclerotic intimal lesions and matrix metalloproteinase 9 expression in apolipoprotein E-deficient mice. Journal of Endocrinology 210 37-46. (doi:10.1530/ JOE-10-0420)
Strittmatter W, Weckesser J, Salimath PV \& Galanos C 1983 Nontoxic lipopolysaccharide from Rhodopseudomonas sphaeroides ATCC 17023. Journal of Bacteriology 155 153-158.

Sun Y \& Pearlman E 2009 Inhibition of corneal inflammation by the TLR4 antagonist Eritoran tetrasodium (E5564). Investigative Ophthalmology \& Visual Science 50 1247-1254. (doi:10.1167/iovs.08-2628)

Ta NN, Schuyler CA, Li Y, Lopes-Virella MF \& Huang Y 2011 DPP-4 (CD26) inhibitor alogliptin inhibits atherosclerosis in diabetic apolipoprotein E-deficient mice. Journal of Cardiovascular Pharmacology 58 157-166. (doi:10.1097/FJC.0b013e31821e5626)

Theuma P \& Fonseca VA 2003 Inflammation and emerging risk factors in diabetes mellitus and atherosclerosis. Current Diabetes Reports 3 248-254. (doi:10.1007/s11892-003-0072-3)

Victorov AV, Gladkaya EM, Novikov DK, Kosykh VA \& Yurkiv VA 1989 Lipopolysaccharide toxin can directly stimulate the intracellular accumulation of lipids and their secretion into medium in the primary culture of rabbit hepatocytes. FEBS Letters 256 155-158. (doi:10.1016/ 0014-5793(89)81738-7)

Visintin A, Halmen KA, Latz E, Monks BG \& Golenbock DT 2005 Pharmacological inhibition of endotoxin responses is achieved by targeting the TLR4 coreceptor, MD-2. Journal of Immunology $\mathbf{1 7 5}$ 6465-6472.

Wang RP, Yao Q, Xiao YB, Zhu SB, Yang L, Feng JM, Li DZ, Li XL, Wu JJ \& Chen J 2011 Toll-like receptor 4/nuclear factor- $\kappa B$ pathway is involved in myocardial injury in a rat chronic stress model. Stress 14 567-575. (doi:10.3109/10253890.2011.571729)

Zipris D 2010 Toll-like receptors and type 1 diabetes. Advances in Experimental Medicine and Biology 654 585-610. (doi:10.1007/978-90481-3271-3_25)

Received in final form 5 October 2012

Accepted 11 October 2012

Accepted Preprint published online 11 October 2012
() 2013 Society for Endocrinology Printed in Great Britain
Published by Bioscientifica Ltd. 